\title{
Comparison of Measurement Methods of LV Grid Access Impedance in the Frequency Range Assigned to $\mathrm{Nb}$-Plc Technologies
}

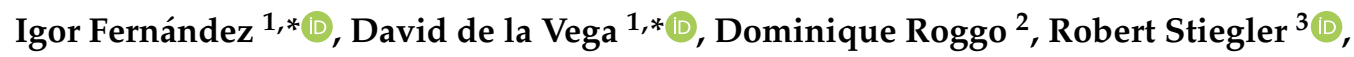 \\ Lino Capponi ${ }^{2}{ }^{\circledR}$, Itziar Angulo ${ }^{1}$, Jan Meyer ${ }^{3}$ and Amaia Arrinda ${ }^{1}$ \\ 1 Department Communications Engineering, University of the Basque Country (UPV/EHU), 48013 Bilbao, \\ Spain; itziar.angulo@ehu.eus (I.A.); amaia.arrinda@ehu.eus (A.A.) \\ 2 Institute Systems Engineering, Haute École Spécialisée de Suisse Occidentale (HES-SO) Valais-Wallis, \\ 1950 Sion, Switzerland; dominique.roggo@hevs.ch (D.R.); lino.capponi@gmx.ch (L.C.) \\ 3 Institute of Electrical Power Systems and High Voltage Engineering at Technische Universitaet \\ Dresden (TUD), 01062 Dresden, Germany; robert.stiegler@tu-dresden.de (R.S.); \\ jan.meyer@tu-dresden.de (J.M.) \\ * Correspondence: igor.fernandez@ehu.eus (I.F.); david.delavega@ehu.es (D.d.l.V.)
}

Received: 26 July 2019; Accepted: 7 October 2019; Published: 12 October 2019

\begin{abstract}
The paper presents and evaluates three advanced methods for the characterization of the low-voltage (LV) grid access impedance for the frequency range assigned to Narrow Band-Power Line Communications (NB-PLC): $9 \mathrm{kHz}$ to $500 \mathrm{kHz}$. This study responds to the recent demand from both regulatory bodies and Distribution System Operators about the need for accurate and validated methods for this frequency band, due to the limited knowledge of the impedance values in the electrical grid and their influence on NB-PLC transmission channels. In this paper, the results of a collaborative work to develop different proposals to overcome the challenges for the proper characterization of the frequency and time-varying grid impedance, from different theoretical approaches, are presented. The methods are compared in a controlled and isolated scenario: the impedance characterization of passive filters. Then, the results are validated two-fold: first, against theoretical simulations, based on the schematics provided by the manufacturer, and second, against the measurement results of a precision impedance meter, used as a reference of accuracy. The results demonstrate a high degree of precision of the three proposals to characterize the access impedance of the LV grid.
\end{abstract}

Keywords: impedance measurement; measurement techniques; electric variables measurement; communication channels; electromagnetic compatibility and interference

\section{Introduction}

The influence of the access impedance of the grid around the fundamental frequency of the supply voltage $(50 / 60 \mathrm{~Hz})$ for setting Electromagnetic Compatibility (EMC) requirements is well known [1]. Accordingly, reference values for network impedance below $2 \mathrm{kHz}$ and between $2 \mathrm{kHz}-9 \mathrm{kHz}$ can be found in the normative documents [2,3]. Moreover, some solutions to estimate and overcome the grid impedance variations below $2 \mathrm{kHz}$ have been developed [4-7].

However, for frequencies above $9 \mathrm{kHz}$, there are neither validated methods nor reference values for the access impedance of the grid. In this frequency band, the low-voltage (LV) grid impedance shows varying values over frequency and also over time, depending on the actual line configuration and the loads connected to the grid by the users at a certain moment [8,9]. Recent studies highlight that the network impedance not only represents a major factor for EMC in the frequency band above $9 \mathrm{kHz}[1,8,10]$, but also a significant influence on Narrow Band-Power Line Communications 
(NB-PLC) [11-14]. Results and models for low frequencies are not applicable to frequencies above 9 $\mathrm{kHz}[1,2,9,14]$.

This study provides research results about the first collaborative work where three different proposals for measuring $\mathrm{LV}$ grid impedance between $9 \mathrm{kHz}$ and $500 \mathrm{kHz}$ are presented and compared. The three presented methods try to overcome, with different strategies, the challenges for the proper characterization of the frequency and time-varying impedance. The methods are described in Sections 3-5, and compared in Section 6. In Section 7, an evaluation of the methods is performed, first, against computer simulations, and second, against the measurement results of a precision impedance meter, used as a reference of accuracy.

\section{The Effects of the Grid Impedance on Narrow Band-Power Line Communications (NB-PLC)}

Narrow Band Power Line Communications (NB-PLC) are used by the Distribution System Operators (DSO) to transmit data over the lines between smart meters and data concentrators. These communication systems currently work in the CENELEC-A band in Europe ( $3 \mathrm{kHz}-95 \mathrm{kHz})$, but also in higher frequencies in America and Asia (150 kHz-500 kHz) [1,15]. In particular, the frequency bands for NB-PLC are the FCC band (10-490 kHz) in the USA, the ARIB band (10-450 kHz) in Japan and the frequency range $3 \mathrm{kHz}-500 \mathrm{kHz}$ in China.

In Europe, the CENELEC-A band (3-95 kHz) is reserved for communications of DSOs in NB-PLC systems compliant with the standard EN 50065-1 [16], the CENELEC-B, C and D bands, from $95 \mathrm{kHz}$ to $148.5 \mathrm{kHz}$, are planned for the use of NB-PLC in other environments, such as in-home services [17], with certain limits established by the EN 50065-1 [16]. However, in view of the increasing communication problems due to the noise and interfering emissions in the CENELEC-A band and the need for higher bandwidths to allocate new services, several European markets are considering the frequency band up to $500 \mathrm{kHz}[1,18-20]$. This frequency range seems to present lower noise levels and higher access impedance magnitudes, with respect to the CENELEC-A band. In this line, some field trials to evaluate the propagation properties of the electrical grid have been developed in recent years, mainly to evaluate the amplitude of the noise and interfering emissions $[1,18,21-23]$ and the transmission losses $[18,24]$ in this frequency range. These studies demonstrate the need for a detailed characterization (in amplitude, time variability and frequency range) of the emissions generated by Distributed Energy Resources (DERs) and the strong influence of both the grid topology and the distance between PLC modems in the transmission losses. The detailed characterization of these aspects and their influence on the proper performance of the NB-PLC are currently under analysis. Lastly, some of the NB-PLC technologies developed in Europe are already prepared to be used up to $500 \mathrm{kHz}$, such as G3-PLC [25], or they have released specific configurations for the frequency range up to $500 \mathrm{kHz}$, such as PRIME 1.4 [19,26].

In summary, the access impedance of the LV grid is a major factor related to the performance of NB-PLC, regardless of the transmission technology, as it is one of the most relevant parameters when characterizing the electric grid as a signal propagation medium $[1,2,8,9,12,13]$. For this reason, the approach of this work covers the frequency range up to $500 \mathrm{kHz}$.

Within this frequency range, the magnitude of the LV access impedance varies with frequency, from values around $1 \mathrm{Ohm}$ at lower frequencies, to several tenths of Ohms at higher frequencies, and at specific frequencies where resonance effects occur [1,27-29], with values of a few Ohms [1,27,30,31]. Impedance values may also vary between rural and urban areas $[27,28]$ due to the different grid topologies and the higher number of customer loads connected to the grid in the urban environments. For long cables and high frequencies, the line impedance is dominated by the characteristic impedance of the cable [32]. Lastly, the connection/disconnection of the consumer loads, and their inductive or capacitive behavior, causes a variation in time of the grid impedance.

These variable low magnitudes of the LV access impedance present two problems in the development of NB-PLC systems. First, the very low values imply the need for injecting high current values, in order to transfer appreciable values of voltage to the grid [27,32]. Second, the coupling losses from the transmitter to the PLC network, due to the impedance mismatching between the PLC 
transmitters and the electrical grid $[16,27]$ (the matching condition occurs for the conjugate impedance between modem and propagation medium [16]). These conditions complicate the implementation of costly PLC transmitters with very low output impedance, which should also adapt to the variation with time and frequency of the grid [32].

With respect to the impedance phase, some studies show that the variation in time of the phase of the propagation channel is lower than $\pm 10^{\circ}$ in the CENELEC-A band, which enables the use of the coherent modulation schemes $[15,33]$. On the contrary, the variation in frequency of the phase of the propagation channel may be higher than $90^{\circ}$ for a difference of an octave [33].

The impedance mismatching in the electrical grid, generated by different types and lengths of cables and by different types of loads that are connected and disconnected at homes and industries, causes a reduction of the signal level in the receiver. This leads to a decrease in the transmission range [34], a significant reduction of the data rate [35] and, in the worst case, the communication lost between devices. The impact of the impedance may be of greater extent if, apart from the above-mentioned effect, the impedance varies within the frequency range of the PLC transmission channel. As a representative example, Figure 1 shows results from field measurements in Spain, where the variation of the grid impedance within the PLC transmission channel generates great differences on the signal level at the receiver. In these cases, the quality of the communication can be significantly degraded. This effect is particularly amplified by the variation with time of the grid impedance, which makes the consequences of this type of degradation difficult to predict [14].

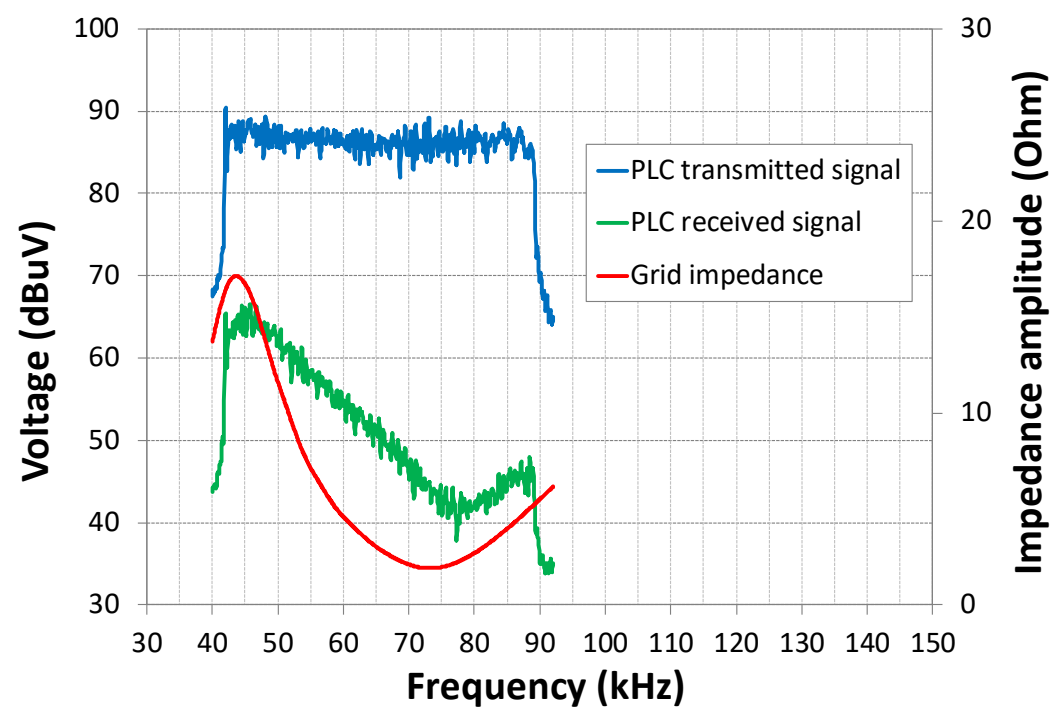

Figure 1. Impact of grid impedance on the communication between two smart meters located at the ends of a grid section: spectra of both Narrow Band Power Line Communications (NB-PLC) signals, registered in the transmitter and in the receiver, and frequency response of the grid impedance measured for that grid section.

Accordingly, accurate measurement methods of the grid impedance that could be used in the field are needed to provide impedance reference values for equipment tests and PLC immunity laboratory tests. Moreover, detailed descriptions of time and frequency variability would provide useful information for the proper characterization of the communication channel and for solving challenging situations in the field. For this reason, the characterization of the time- and frequency-dependent grid impedance above $9 \mathrm{kHz}$ is being demanded by the regulatory and standardization agents $[1,8]$.

Moreover, the grid impedance is related to the propagation of the interfering emissions generated by some electronic devices connected to the grid, which degrade the quality and reliability of NB-PLC. These emissions are mainly generated by new power electronic topologies, operating with switching frequencies above $2 \mathrm{kHz}$, in order to optimize the energy efficiency. The increasing number of such 
devices leads to more frequent and higher levels of emissions in frequencies above $9 \mathrm{kHz}[1,36]$. If the voltage levels of the emissions exceed the compatibility levels, the performance of other connected devices can be disturbed [36,37]. Both the voltage levels and the propagation distances of these emissions are highly determined by the grid impedance. In this line, the analysis proposed in Reference [21] for the characterization of noise and non-intentional emissions generated by the electronics devices connected to the grid, which propagate through the propagation medium, together with the assessment of the transmission losses described in Reference [24], are complementary methods for a comprehensive characterization of the electrical grid as a propagation medium for NB-PLC. The use of passive filtering is one of the techniques analyzed to mitigate the effects of noise, but the input and output impedances of these filters, and their relation to the impedances of grid and smart meters, are relevant aspects to be considered [38].

The proper use of different modulation and coding techniques in NB-PLC, with variable levels of robustness, is a key aspect to face the different types of propagation channel disturbances, including the time and frequency variations of grid impedance and robustness against different types of noise [23]. The evaluation of the transmission channel by the NB-PLC modems is the basic step for the development of real time methods for adaptive configuration of the coding and modulation schemes used for data transmission. In Reference [39], several adaptive communication approaches to face the negative effects of noise are discussed and evaluated in laboratory and field measurements. Other studies analyze the use of advanced signal processing techniques to be applied in Advanced Metering Infrastructures, based on the channel estimation, for G3-PLC [40]. Other adaptive techniques are based on adaptive spectrum assignment, in order to avoid channel notches and narrowband interferences [41,42], though this mechanism is already included in the technical specifications of G3-PLC ('Adaptative Tone Mapping'), by dividing the transmission channel in sub-channels and removing the data from the affected sub-channels [25].

The first steps for EMC standardization were taken with the definition of compatibility levels for voltage [43], but the determination of the emission limits requires a wide knowledge about the grid impedance. The common approach used for frequencies below $2 \mathrm{kHz}$, which is a simplified representation of the grid impedance by an impedance line, is not suitable for higher frequencies, as it will lead to very conservative values.

For all the above-mentioned reasons, field measurements of the grid impedance for frequencies above $9 \mathrm{kHz}$ are being demanded by regulatory bodies, and the first stage for that is the definition of accurate measurement methods of the grid impedance. Some preliminary results of field measurements on the grid impedance for higher frequency bands can be found in the literature [44-48], however, there is no commonly accepted measurement method up to $500 \mathrm{kHz}$, validated with comparable results from lab measurements, and supported by standardization agents [1].

\section{Method I: IGOR-Meter}

Method I was developed by the Institute Systems Engineering at HES-SO Valais-Wallis [49,50]. In the design of the so-called IGOR-Meter, particular attention was put on flexibility, high accuracy, a wide frequency range, portability and low impact on other equipment connected to the grid. Based on the previous experience of this group, grid impedance measurements were applied in the evaluation of NB-PLC communication channels in the lab and in the field [51].

The main components are a small current generator directly coupled to the LV line, external voltage and current probes and a high-performance data conversion and signal treatment unit. The impedance is calculated for a set of frequency bins covering the whole frequency range, where the number and width of the bins is configurable by the user. The impedance value for each frequency bin is calculated by applying Synchronous or Dual-Phase Demodulation (DPD). 


\subsection{Measurement Setup for the IGOR-Meter}

The measuring setup is represented in Figure 2. The single frequency current source is based on a linear Class A/B type of amplifier with a frequency range from DC to $500 \mathrm{kHz}$, supplied from a $\pm 400 \mathrm{~V}$ DC bus. At any time, the DC voltage source has a higher absolute voltage than the grid at the measuring point, allowing the current source to be directly fed into the LV AC grid without any coupler. The line voltage at the coupling point is measured by an active isolated $100 \mathrm{MHz}$ differential amplifier (SI-9101), while the current fed to the grid is measured either with the help of an instrumentation Current Transformer (Pearson Model 110) or with the help of a $30 \mathrm{MHz}$ high-precision Rogowski coil (PEM UK CWT015). The $\pm 400 \mathrm{~V}$ DC bus amplifier and the signal processing units are supplied from a 24 VDC battery through integrated DC/DC converters, in order to avoid any interference with the measured grid section.

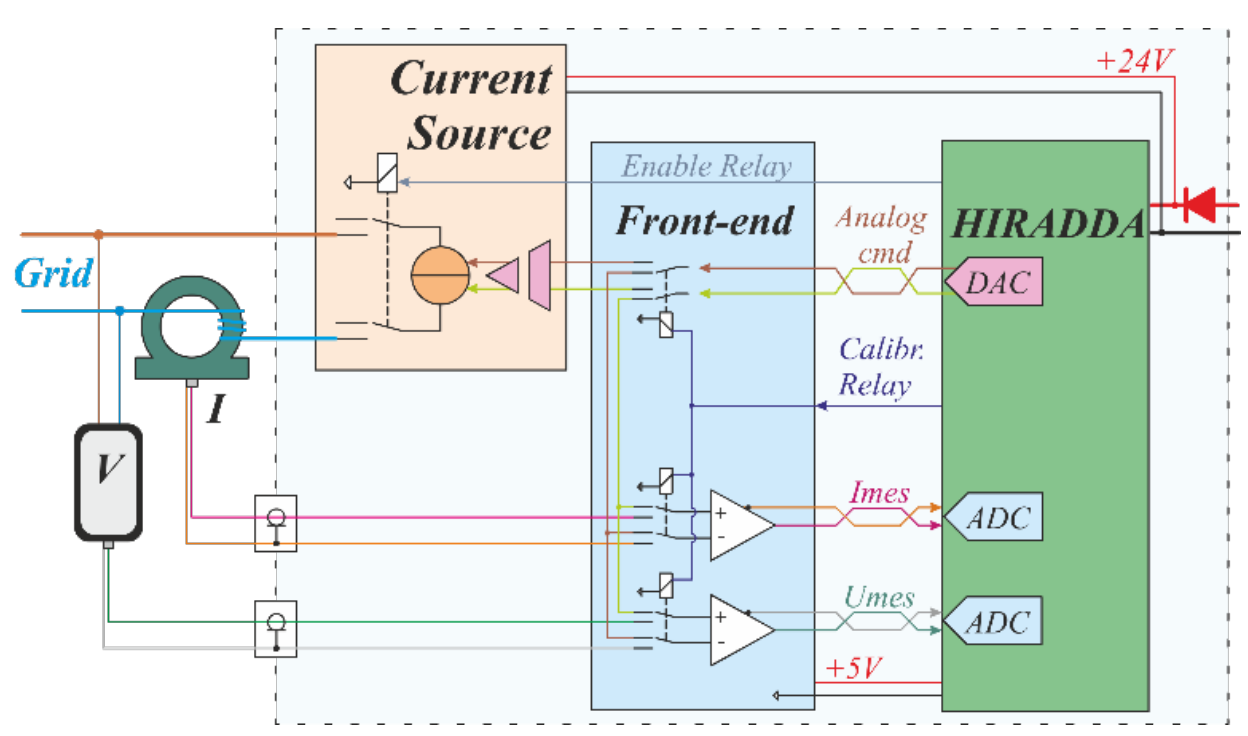

Figure 2. Block diagram of the IGOR-Meter developed by the HES-SO and setup for the grid impedance measurement.

The HiRADDA acquisition and data processing unit generate the current reference for the amplifier and calculate the impedance of each frequency bin on the basis of measured current and voltage values (see Figure 2). The unit is based on a Xilink 7 FPGA and it was specifically developed at HES-SO for impedance measurement purposes (see Figure 3). Additionally, high resolution (24 bits) and large bandwidth (4 MSamples/s) DACs were selected in order to reach the highest possible accuracy and flexibility for research activities in this domain, making possible the measurement of grid impedance at frequencies between $100 \mathrm{~Hz}$ and $1 \mathrm{MHz}$.

The front-end unit interfaces the external voltage and current probes to the processing unit with adapted signal gains and limits. An internal calibration loop, where the signal generator can be directly connected to the data acquisition channels, ensures that the signal levels are limited and adequate for optimal accuracy. Both voltage and current probes are characterized in magnitude and phase over the whole working frequency range, allowing calibration of the signal processing. An external laptop computer controls the whole system. 


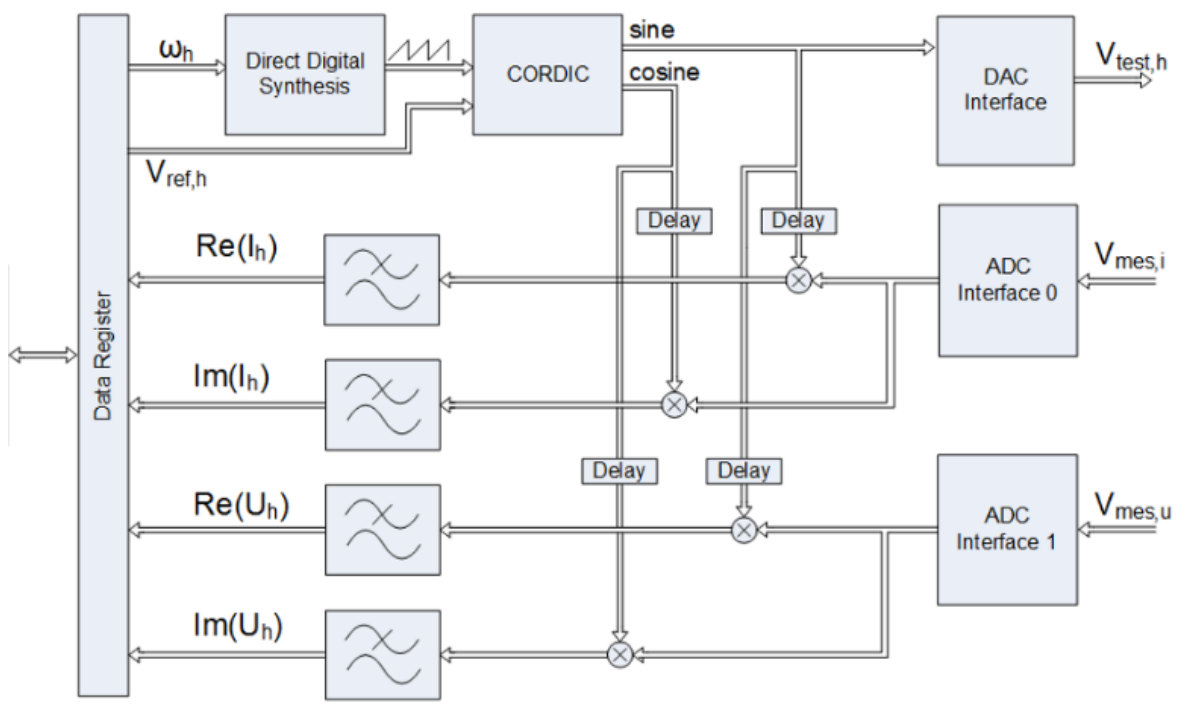

Figure 3. Fast digital signal processing of a Dual Phase Demodulation (DPD) implemented in a high-performance FPGA for Method I.

\subsection{Data Processing}

The Dual-Phase Demodulation (DPD) applied in the IGOR-Meter relies on the Lock-In Amplifier detection technique, described in Reference [52]. According to the block schematic represented in Figure 3 , a sinusoidal reference signal $v_{\text {test }, h}(t)$ at the frequency bin ' $h$ ', and a corresponding excitation current of $200 \mathrm{~mA}$ amplitude, is generated by the HiRADDA unit and fed to the grid by the current source amplifier (see Figure 2).

The measured voltage and current values $v_{m e s, u, i}(t)$ are multiplied after $\mathrm{A} / \mathrm{D}$ conversion with the perturbation reference. The DC components obtained by low pass filtering of those products represent the real components of the voltage $\operatorname{Re}\left(U_{h}\right)$ and respectively current $\operatorname{Re}\left(I_{h}\right)$, of the frequency bin under tests. The resulting DC part $v_{d}$ is not time-dependent and contains only information of the components of the frequency bin ' $h$ '. The imaginary components $\operatorname{Im}\left(U_{h}\right)$ and $\operatorname{Im}\left(I_{h}\right)$ are obtained with a similar process using a $90^{\circ}$ shifted reference.

The amplitude and phase of the impedance $\underline{Z}_{h}$ of each frequency bin is computed by dividing the measured voltage by the corresponding current value. A description of the process, including mathematical formulation, can be found in Reference [49].

\subsection{Advantages and Limitations}

The key advantage of the Dual-Phase Demodulation process relies on the capacity to measure very low-level signal components at a specific frequency, even in a noisy environment. According to Ohm's law, the measured signal in Volts is directly proportional to the current fed to the grid and to the grid impedance $Z_{h}$ at the frequency bin under test. The system was designed to measure voltage components in the range of $100 \mathrm{mV}$, in order to get a good accuracy on the measurements at impedances below $1 \mathrm{Ohm}$, even when using a very low excitation current, in the order of $100 \mathrm{~mA}$. Using a low current does not only require a smaller power amplifier, it also guarantees that the excitation current used in the invasive method will not damage or interfere with equipment connected to the grid. The use of a direct amplifier coupling to the grid makes an accurate control of the excitation current possible, saving the cost, weight and losses of a wideband coupler.

The drawback of the Dual-Phase Demodulation method is that measurements at low frequencies with high resolution in frequency may be time consuming. In fact, the filtering out of the AC components in the demodulation process requires a stabilization time after each frequency step. Experience show good results when a stabilization period of 5 to 10 cycles at each frequency bin ' $h$ ' is 
applied. In consequence, the measurement time increases when the number of frequency bins selected by the user is high.

The stabilization process becomes a particular issue in case of time-dependent grid impedance variations and measurement within one fundamental frequency cycle $(50 / 60 \mathrm{~Hz})$. On one hand, the measurement should be fully processed within a minimal time resolution step (below $1 \mathrm{~ms}$ typically). On the other hand, because of the time variance of $Z_{h}$ itself, a stabilization period during the signal treatment process must be respected even when no frequency step between two measurements occur. According to computer simulations, the DPD method could be practically used to measure time variant grid impedance within $50 \mathrm{~Hz}$ cycles. Sufficient accuracy would, however, only be achieved for frequencies above $9 \mathrm{kHz}$.

Lastly, a high noise level can cause significant error in magnitude and phase, in particular with time-varying signals. Active signals will, however, generate discontinuity in the phase measured, which can be detected, so that corrupted results can be easily selected out.

\section{Method II: UPV/EHU Method}

\subsection{Fundamentals of the Method}

The method developed by the University of the Basque Country (UPV/EHU) is based on the measurement of the voltage and current values of ad-hoc test signals injected in the grid $[50,53]$. The test signals are injected in a controlled way into the grid, with a limited amplitude, in order to avoid damage on other devices connected to the grid. Then, the voltage and current values are acquired, synchronously, during a period of several seconds (this period is configurable by the user). The post-processing of the registered data provides the spectral characterization of voltage and current signals. The amplitude and phase of the grid impedance are calculated as the ratio between the voltage and current values for each frequency bin, within the frequency range assigned to NB-PLC, up to $500 \mathrm{kHz}$. A scheme of the measurement setup is shown in Figure 4.

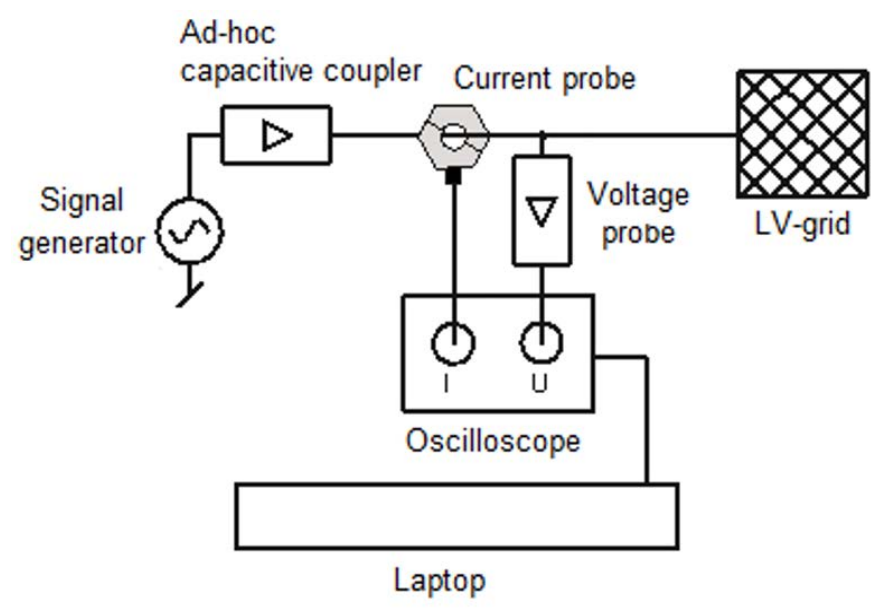

Figure 4. Measurement setup of the method developed by the UPV/EHU for the grid impedance measurement.

The signal injected in the grid is a single frequency sweep for the frequency range under analysis. The level of the transmitted signal, the sweep time and the frequency range are configurable by the user in the signal generator. The main advantage of the sweep signal is that it provides the spectral characterization for the whole frequency range in a single measurement. Moreover, the configuration of the sweep time, together with the recording of consecutive measurements, allows the user to obtain information about the time variation of the grid impedance for the whole frequency range. The resolution in the time variation of the grid impedance is directly related to the sweep time of the injected signal, and therefore, it is configurable by the user. 
For synchronous measurement of voltage and current, a high-resolution oscilloscope digitizes the acquired signals at a high sampling rate. A dedicated software in the laptop configures and records the oscilloscope recordings. For decoupling the generated signal from the LV grid, a capacitive probe and a current probe are used (see Figure 4).

In order to couple the generated signal into the grid, a capacitive probe has been specifically designed for this system. This coupler does not modify the characteristics of the generated signal, and it protects the signal generator from over-voltages caused by fast transient disturbances. The voltage probe has been designed to achieve several requirements. First, it must reject signals below $9 \mathrm{kHz}$ (mainly 50/60 Hz component and low-order harmonics), in order to protect the measuring equipment. The fundamental and the low-order harmonics are filtered out by the voltage probe with an attenuation greater than $107 \mathrm{~dB}$. This suppression of high-amplitude signals highly increases the amplitude resolution of the system, since the sampling resolution is completely adapted to the amplitude of the voltage used to measure the grid impedance, instead to the voltage level of the fundamental. Second, signals above $500 \mathrm{kHz}$ must be filtered out to avoid coupling of radio signals and aliasing effects. Lastly, it must provide a flat frequency response in the frequency band of interest for the wide range of typical grid impedance values $(1 \Omega$ to $50 \Omega)[1,27,28]$. The characteristics and validation of this voltage probe are described in Reference [54].

For the sake of accuracy, the current probe and the equipment for voltage measurement (including connecting cables, voltage probe and oscilloscope) have been carefully characterized and this calibration is applied in the post-processing software.

\subsection{Signal Processing}

The processing of the recorded signals is the core of the assessment procedure of this method. It is based on three main steps: signal windowing, Fourier analysis and impedance assessment. Therefore, different resolutions in time and frequency domains are possible, simply modifying the configuration of the signal processing of the recorded measurements.

First, once the voltage and current values generated by the injected signal have been recorded, a sliding windowing in time is applied to select a set of synchronous samples of $(\mathrm{V}, \mathrm{I})$ with high resolution. A representative configuration is a sliding window of $20 \mathrm{~ms}$, with a shift step of $5 \mathrm{~ms}$ (75\% of overlapping between consecutive windows).

Second, Fourier analysis is applied separately to each set of (V, I) samples, in order to obtain spectral characterization. As a result, the single frequency sweep injected by the signal generator can be clearly identified and selected. The Fourier analysis does not take into account the frequency bins below $20 \mathrm{kHz}$, and therefore, the attenuated component at $50 \mathrm{~Hz}$ is not considered in the Fourier analysis. The frequency resolution depends on the assessment configuration, but a granularity of a few $\mathrm{Hz}$ is easily feasible, if required. For example, a resolution of $50 \mathrm{~Hz}$ is obtained with a windowing of $20 \mathrm{~ms}$. The performance of the measurement equipment on the acquired values is also considered in the assessment of the impedance. Moreover, a correction factor to account for the phase difference between the voltage and current probes is applied.

Lastly, the impedance is calculated from the rectified results of $(\mathrm{V}, \mathrm{I})$ for the whole frequency range (up to $500 \mathrm{kHz}$ ). Typical configuration of the data processing leads to a resolution granularity of $50 \mathrm{~Hz}$, although $5 \mathrm{~Hz}$ resolution can be achieved by applying a time sliding window of $200 \mathrm{~ms}$. The accuracy of the results requires that both $\mathrm{V}$ and I amplitudes are higher than the noise levels present in the grid. To ensure this requirement, the noise levels along the frequency range are calculated, and then, the criterion of considering only signal levels of a certain margin above the noise level is applied in the software processing, in order to ensure that high noise levels do not distort the assessments. Moreover, signal and noise levels are represented as an intermediate result, in order to allow the user to check that the signal-to-noise ratio is sufficient in the whole frequency range, and therefore, to guarantee a high degree of accuracy in the results. 
As all the measurements and signal processing consider the samples of $(\mathrm{V}, \mathrm{I})$, results include both amplitude and phase of the grid impedance.

For the sake of accuracy, only the $\mathrm{V}$ and I levels with a margin of $10 \mathrm{~dB}$ above the noise level are considered in the calculation. For that, the noise levels in the frequencies where there is no presence of the injected signal sweep are calculated and compared to the $(\mathrm{V}, \mathrm{I})$ levels.

\subsection{Advantages and Limitations}

With this method, the measurement requires only a few seconds. Moreover, the post-processing allows for obtaining different types of results and different levels of resolution in time and frequency, without the need for taking new measurements.

The fundamental and the low-order harmonics are filtered out by the voltage probe (attenuation > $107 \mathrm{~dB}$ ). This suppression of high-amplitude signals highly increases the amplitude resolution of the system, since the sampling resolution is completely adapted to the amplitude of the voltage used to measure the grid impedance, rather than the voltage level of the fundamental.

Furthermore, the method does not require the synchronization to the fundamental frequency, which simplifies the measurement procedure and allows the use of commercially available equipment (oscilloscope, signal generator for the sweep single tone and voltage and current probes), except for the capacitive coupler to protect the signal generator. This implies a high degree of replicability of the measurement system by third parties.

This measurement method has been used in field trials developed in Spain, in collaboration with the DSO Iberdrola, in order to characterize the access impedance of the LV grid, both in rural and urban scenarios, up to $500 \mathrm{kHz}$ [28]. In particular, the system used in the field trials was prepared to inject two types of ad-hoc signals into the grid: a single frequency sweep, as described in the previous sections, and controlled NB-PLC signals according to the transmission technology used by the DSO involved in the trials. In both cases, the signal level, the frequency and other characteristics of the injected signals was configurable. The results of this measurement campaign show a great influence of the grid topology (number and length of branches) and the number and distance of the consumer loads [28].

\section{Method III: TUD Method}

\subsection{Hardware}

The layout of the measurement system proposed by TUD is shown in Figure 5. This system is the further evolution of the system described in Reference [45]. It consists of the following main components:

- Linear amplifier current source for grid excitation

- Integrated voltage and current measurement

- Additional voltage input for external current probes

- Automated power supply disconnection and buffering capacitor

The injected current is generated using a linear amplifier with a maximum output current of $3 \mathrm{~A}$, up to $200 \mathrm{kHz}$, with a maximum output power of $1 \mathrm{kVA}$. The output current level is automatically adapted to the situation at the connection point, so that an excitation of the grid not higher than $1 \mathrm{~V}$ is ensured, in order to not influence on the connected loads.

The output current is measured internally, while the voltage of the grid is measured at the connection point, so that a four-terminal measurement is realized, and the impedance of the measurement cables does not influence the measurement results. An additional voltage measurement input is available to connect external current probes for impedance measurements of loads connected to the grid. Both voltage and current signals are recorded at a sampling rate of $10 \mathrm{MS} / \mathrm{s}$. 
In order to avoid a potential disturbance of the system power supply on the measurement of the impedance, while measuring, the system is powered from a grid-independent source.

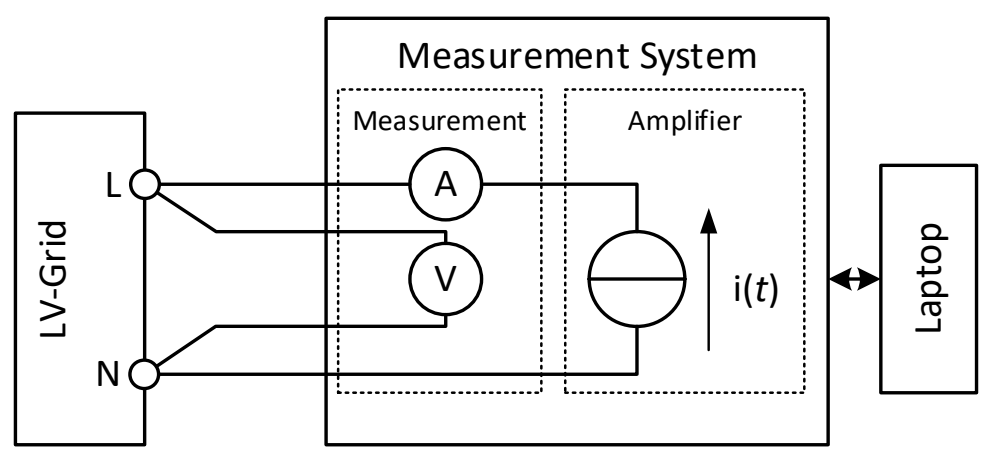

Figure 5. Scheme of the TUD measurement system.

\subsection{Measurement Algorithm}

The frequency resolution of the measurement (number of the frequency bins) is configurable by the user. The measurement of the impedance is implemented as a stepwise single frequency sweep. The impedance for each frequency is measured in single measurement steps. For each measurement step, voltage and current are sampled for $440 \mathrm{~ms}$, while a sinusoidal current is injected in the grid only for $220 \mathrm{~ms}$. Therefore, a measurement step consists of two states, one with current injection (State A) and one without current injection (State B). The length of $220 \mathrm{~ms}$ for each state ensures a minimum of 10 complete voltage fundamental cycles for evaluation. Frequencies with high background distortion are identified and can be blanked out

The voltage and current values for each state are calculated by DFT with a rectangular window with a length of 10 voltage fundamental cycles, based on the measurement principle for harmonics according to IEC 61000-4-7 [3]. The network impedance is calculated for the injected frequency with the difference method according to Equation (1).

$$
\underline{Z}(f)=\frac{\underline{U}_{A}(f)-\underline{U}_{B}(f)}{\underline{I}_{A}(f)-\underline{I}_{B}(f)}
$$

The calculated impedance is the mean value over 10 voltage fundamental cycles. The additional feature of measuring the impedance behavior within the fundamental voltage cycle (sub-cycle impedance or cyclostationary impedance) is described in Reference [45].

The whole system was calibrated with external reference impedances, a measurement uncertainty for the impedance of better than $2 \%$ can be ensured over the whole frequency range.

\subsection{Advantages and Limitations}

One unique feature of the system is that the injected frequency is synchronized with a PLL to the fundamental frequency of the grid, so that the injected current matches in a 10 cycles interval of the voltage fundamental without leakage. When the injected frequency and the voltage fundamental are not synchronous, it will lead, depending on the instantaneous voltage of the fundamental frequency, to a leakage that has a strong influence on the measurement result. In other approaches, the fundamental is rejected with a high pass filter, but this limits the frequency range of the measurement. With the synchronization technique, the use of a high pass filtering is not required, so that the measurable frequency range is only limited by the current source. Moreover, the network impedance can also be measured for subharmonic frequencies of the fundamental (e.g., $25 \mathrm{~Hz}$ ). 


\section{Comparison of the Measurement Methods}

In order to provide a better description of the proposed measurement methods, the main characteristics and specifications are outlined in Table 1. Moreover, the advantages and limitations of the systems are summarized in Table 2.

Table 1. Summary of the main characteristics of the proposed measurement methods.

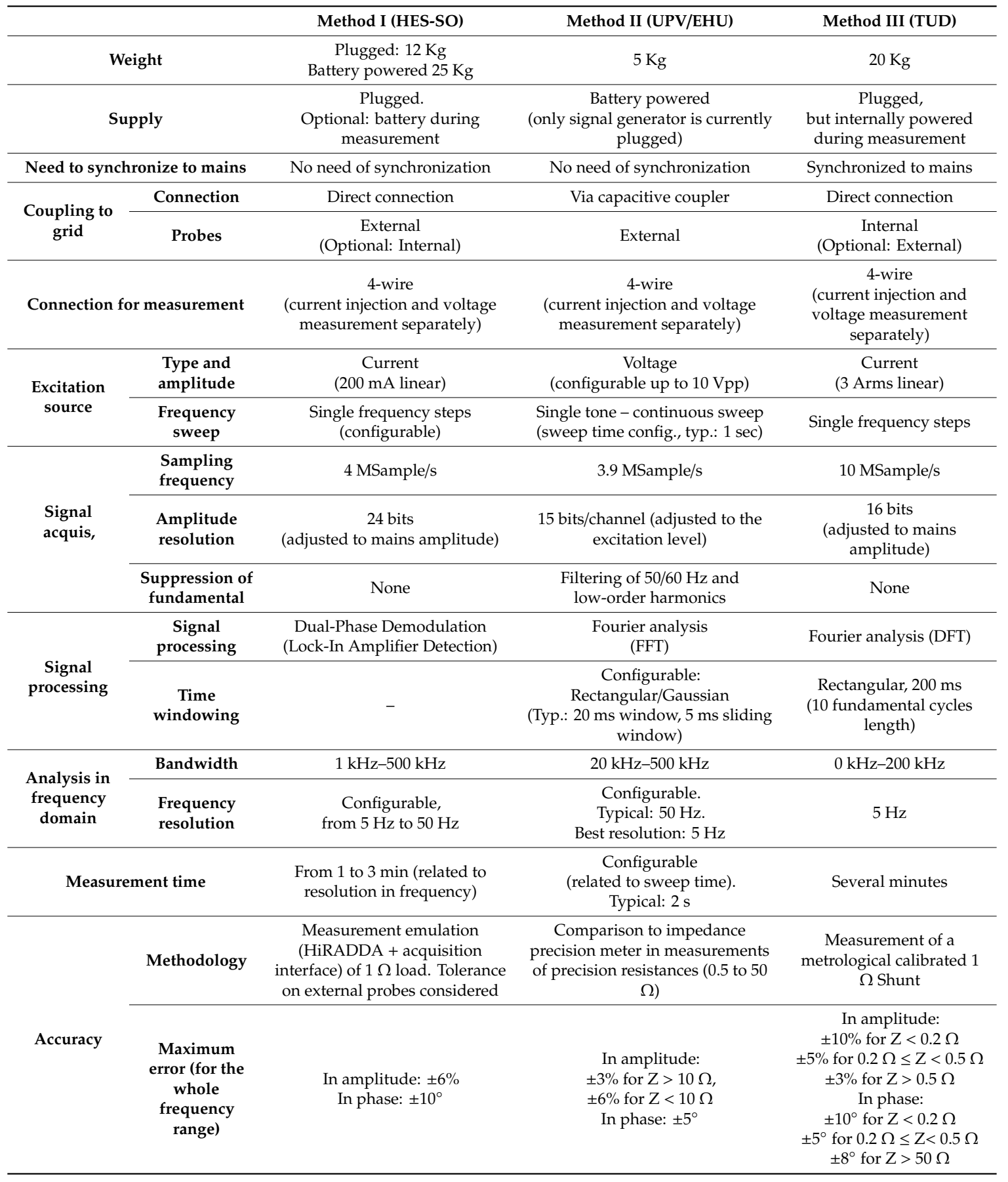


Table 2. Summary of the advantages and limitations of the measurement methods.

\begin{tabular}{|c|c|c|c|}
\hline & Method I (HES-SO) & Method II (UPV/EHU) & Method III (TUD) \\
\hline Advantages & $\begin{array}{l}\text { - Capacity to measure very } \\
\text { low-level signal levels, even in } \\
\text { a noisy environment } \\
\text { Large bandwidth (100 Hz to } \\
\text { 1MHz successfully tested } \\
\text { in lab) } \\
\text { Very high accuracy despite a } \\
\text { reduced perturbation current } \\
\text { (non-intrusive method) } \\
\text { On-line grid or equipment } \\
\text { impedances can be } \\
\text { both measured }\end{array}$ & 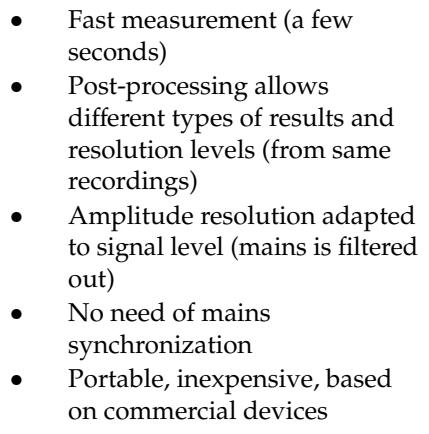 & $\begin{array}{l}\text { Synchronization of injected } \\
\text { current to the fundamental for } \\
\text { a } 10 \text { cycles interval without } \\
\text { leakage } \\
\text { - } \quad \text { Low-frequency range is only } \\
\text { limited by the current source } \\
\text { - } \quad \text { Network impedance can be } \\
\text { measured for subharmonic } \\
\text { frequencies of the fundamental }\end{array}$ \\
\hline Limitations & $\begin{array}{l}\text { - Slow measurements in the low } \\
\text { frequency range } \\
\text { - Expensive }\end{array}$ & $\begin{array}{l}\text { - Currently, no results below } \\
20 \mathrm{kHz}\end{array}$ & - $\quad$ Results up to $200 \mathrm{kHz}$ \\
\hline
\end{tabular}

As it can be observed, the approach of each method is different. Therefore, this comparison allows the evaluation of methods of different basis and signal processing to obtain accurate values of grid impedance in the field.

\section{Results and Analysis}

\subsection{Measurement Scenario}

An exhaustive comparison of the measurement methods has been developed, by applying the methods to the same test scenario. Moreover, it is important to ensure that there is no influence from the grid in the results of the measurements, mainly when significant variations in time and frequency may occur. For this purpose, a laboratory setup under controlled and repeatable conditions was defined for the validation of three methods, additionally, the comparison was based on the measurement of passive devices, in order to ensure that there is no influence from the grid in the lab trials.

Hence, the measurement methods were applied to measure the impedance of a set of EMC filters. These types of filters are commonly used for protection against interference voltage from the mains and potential interferences generated by the equipment connected to the grid, as they apply strong attenuation for some frequencies. These filters show a wide range of impedance values along the PLC frequency band, mainly due to the resonance effects they cause at specific frequencies. Moreover, the schematics of the circuitry are available and can be used for the theoretical calculation. All these aspects are strong advantages to select these devices to evaluate the impedance measurement methods.

In addition, theoretical simulations based on the schematics provided by the manufacturer were also developed and compared to the measurement results.

\subsection{References for the Validation of the Methods}

The schematics of the EMC filters were implemented in ADS (Advanced Design System, [55]) to characterize the spectral performance of each device from simulations, as a reference to evaluate the precision of the results from the measurement methods. The schematics of one of the filters are shown in Figure 6, where numbers 1 and 2 represent ports for electrical line and load, respectively. The input impedance was measured in an open-circuit, therefore, no external load was connected to the filter in $\mathrm{L}^{\prime}-\mathrm{N}^{\prime}$.

Moreover, a precision impedance meter was used as a reference meter, in order to compare the results of the proposed methods to the results obtained with a precision metering equipment. This comparison allows a proper evaluation of the results accuracy provided by each method. 


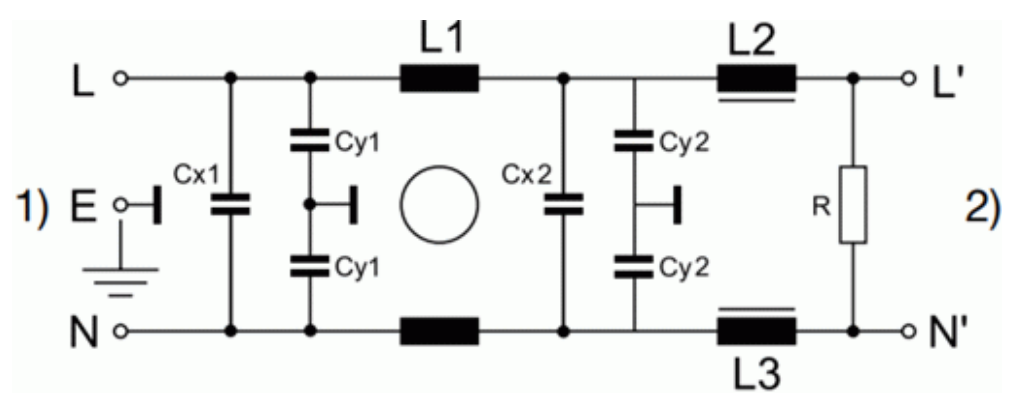

Figure 6. Schematics of the Electromagnetic Compatibility (EMC) filter 2055.

The reference measurement equipment used for this purpose is the Keysight E4990A Impedance Analyzer [56], which provides great accuracy in controlled laboratory measurements of electronic isolated devices, for a wide range of impedance values and for frequencies up to $120 \mathrm{MHz}$. On the contrary, it is not a portable device to be used in the field and it is not valid for measurement of grounded devices. For the frequency band up to $500 \mathrm{kHz}$ and the impedance range addressed in this study, the accuracy of the precision impedance meter is always better than $0.5 \%$, and better than $0.1 \%$ for impedance values greater than $10 \mathrm{Ohms}$ [56]. As this Impedance Analyzer was designed for measurements of non-grounded electronic devices, the EMC filters were not connected to the LV grid, but directly to the terminals of the impedance meter.

\subsection{Results of the Comparison}

The measurement results for some of the EMC filters under test are shown in Figures 7 and 8. Results from ADS simulations and those obtained by the precision impedance meter are also included in the figures, in order to show a reference with theoretical calculations and accurate measurements with calibrated accurate equipment. The accuracy for each method, for a set of representative frequencies, has been assessed by calculating the error values with respect to the results obtained with the precision impedance meter (see Tables 3 and 4).

Table 3. Accuracy of the methods in the measurement of filter 2055, with respect to the results obtained by the impedance precision meter.

\begin{tabular}{|c|c|c|c|c|c|c|}
\hline \multirow[b]{2}{*}{ Freq (kHz) } & \multicolumn{3}{|c|}{ Relative Amplitude Error } & \multicolumn{3}{|c|}{ Phase Error } \\
\hline & HES-SO & UPV/EHU & TUD & HES-SO & UPV/EHU & TUD \\
\hline 10 & $0.17 \%$ & - & $0.18 \%$ & $0.44^{\circ}$ & - & $0.00^{\circ}$ \\
\hline 40 & $2.57 \%$ & $3.19 \%$ & $2.56 \%$ & $1.13^{\circ}$ & $5.86^{\circ}$ & $1.53^{\circ}$ \\
\hline 80 & $2.21 \%$ & $0.12 \%$ & $0.13 \%$ & $0.52^{\circ}$ & $0.87^{\circ}$ & $0.41^{\circ}$ \\
\hline 120 & $4.51 \%$ & $0.35 \%$ & $2.42 \%$ & $0.57^{\circ}$ & $0.43^{\circ}$ & $0.47^{\circ}$ \\
\hline 160 & $0.52 \%$ & $0.93 \%$ & $2.30 \%$ & $0.56^{\circ}$ & $0.50^{\circ}$ & $0.28^{\circ}$ \\
\hline 200 & $0.37 \%$ & $1.00 \%$ & $2.89 \%$ & $0.66^{\circ}$ & $0.26^{\circ}$ & $0.50^{\circ}$ \\
\hline 240 & $0.79 \%$ & $0.97 \%$ & - & $0.75^{\circ}$ & $0.02^{\circ}$ & - \\
\hline 280 & $1.33 \%$ & $1.80 \%$ & - & $0.83^{\circ}$ & $0.01^{\circ}$ & - \\
\hline 320 & $1.91 \%$ & $2.16 \%$ & - & $0.94^{\circ}$ & $0.11^{\circ}$ & - \\
\hline 360 & $2.82 \%$ & $2.59 \%$ & - & $1.05^{\circ}$ & $0.17^{\circ}$ & - \\
\hline 400 & $3.78 \%$ & $2.88 \%$ & - & $1.32^{\circ}$ & $0.75^{\circ}$ & - \\
\hline 440 & $4.51 \%$ & $4.07 \%$ & - & $1.50^{\circ}$ & $0.69^{\circ}$ & - \\
\hline 480 & $5.49 \%$ & $4.47 \%$ & - & $1.65^{\circ}$ & $0.92^{\circ}$ & - \\
\hline Average & $2.38 \%$ & $2.04 \%$ & $1.75 \%$ & $0.92^{\circ}$ & $0.88^{\circ}$ & $0.53^{\circ}$ \\
\hline
\end{tabular}



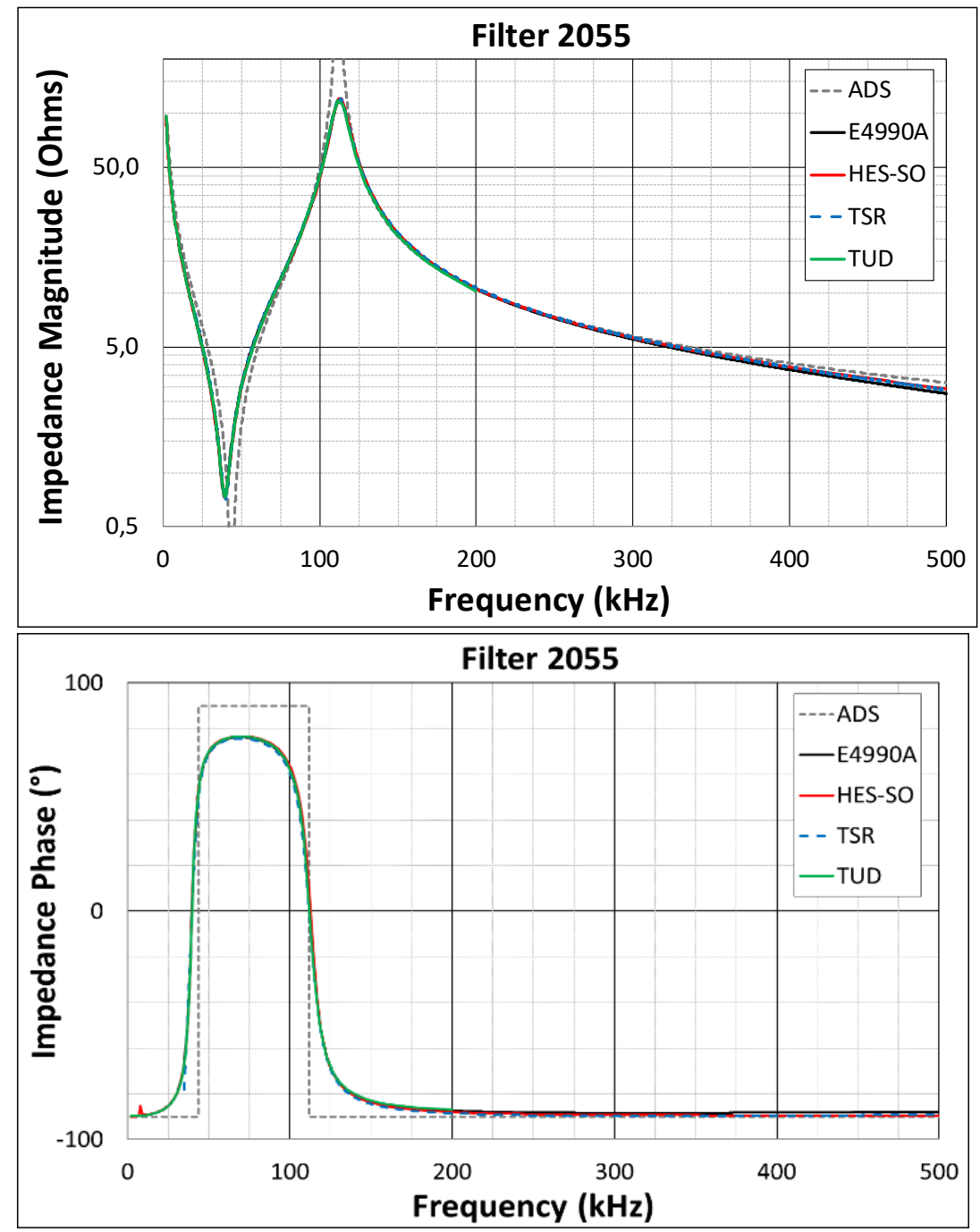

Figure 7. Comparison of simulations and measurement results for filter Reference 2055: (up) magnitude, (down) phase of the impedance.

Table 4. Accuracy of the methods in the measurement of filter 2060, with respect to the results obtained by the impedance precision meter.

\begin{tabular}{ccccccc}
\hline \multicolumn{7}{c}{ Relative Amplitude Error } \\
Freq (kHz) & HES-SO & UPV/EHU & TUD & HES-SO & UPV/EHU & TUD \\
\hline 10 & $2.53 \%$ & - & $0.47 \%$ & $0.01^{\circ}$ & - & $0.00^{\circ}$ \\
40 & $0.99 \%$ & $0.49 \%$ & $0.39 \%$ & $0.21^{\circ}$ & $1.07^{\circ}$ & $0.16^{\circ}$ \\
80 & $1.43 \%$ & $1.37 \%$ & $0.10 \%$ & $0.08^{\circ}$ & $0.91^{\circ}$ & $0.21^{\circ}$ \\
120 & $0.98 \%$ & $1.59 \%$ & $0.29 \%$ & $1.06^{\circ}$ & $0.46^{\circ}$ & $0.08^{\circ}$ \\
160 & $3.13 \%$ & $2.58 \%$ & $0.62 \%$ & $1.41^{\circ}$ & $0.19^{\circ}$ & $0.19^{\circ}$ \\
200 & $17.24 \%$ & $2.52 \%$ & $7.82 \%$ & $6.06^{\circ}$ & $1.87^{\circ}$ & $5.38^{\circ}$ \\
240 & $3.68 \%$ & $0.03 \%$ & - & $1.01^{\circ}$ & $0.34^{\circ}$ & - \\
280 & $0.68 \%$ & $1.32 \%$ & - & $1.56^{\circ}$ & $0.19^{\circ}$ & - \\
320 & $1.21 \%$ & $1.87 \%$ & - & $1.07^{\circ}$ & $0.16^{\circ}$ & - \\
360 & $1.04 \%$ & $2.94 \%$ & - & $1.94^{\circ}$ & $0.07^{\circ}$ & - \\
400 & $1.55 \%$ & $3.23 \%$ & - & $2.35^{\circ}$ & $0.27^{\circ}$ & - \\
440 & $2.37 \%$ & $3.65 \%$ & - & $2.73^{\circ}$ & $0.31^{\circ}$ & - \\
480 & $3.23 \%$ & $4.50 \%$ & - & $3.07^{\circ}$ & $0.58^{\circ}$ & - \\
\hline Average & $3.08 \%$ & $2.17 \%$ & $1.62 \%$ & $1.73^{\circ}$ & $0.54^{\circ}$ & $1.01^{\circ}$ \\
\hline
\end{tabular}




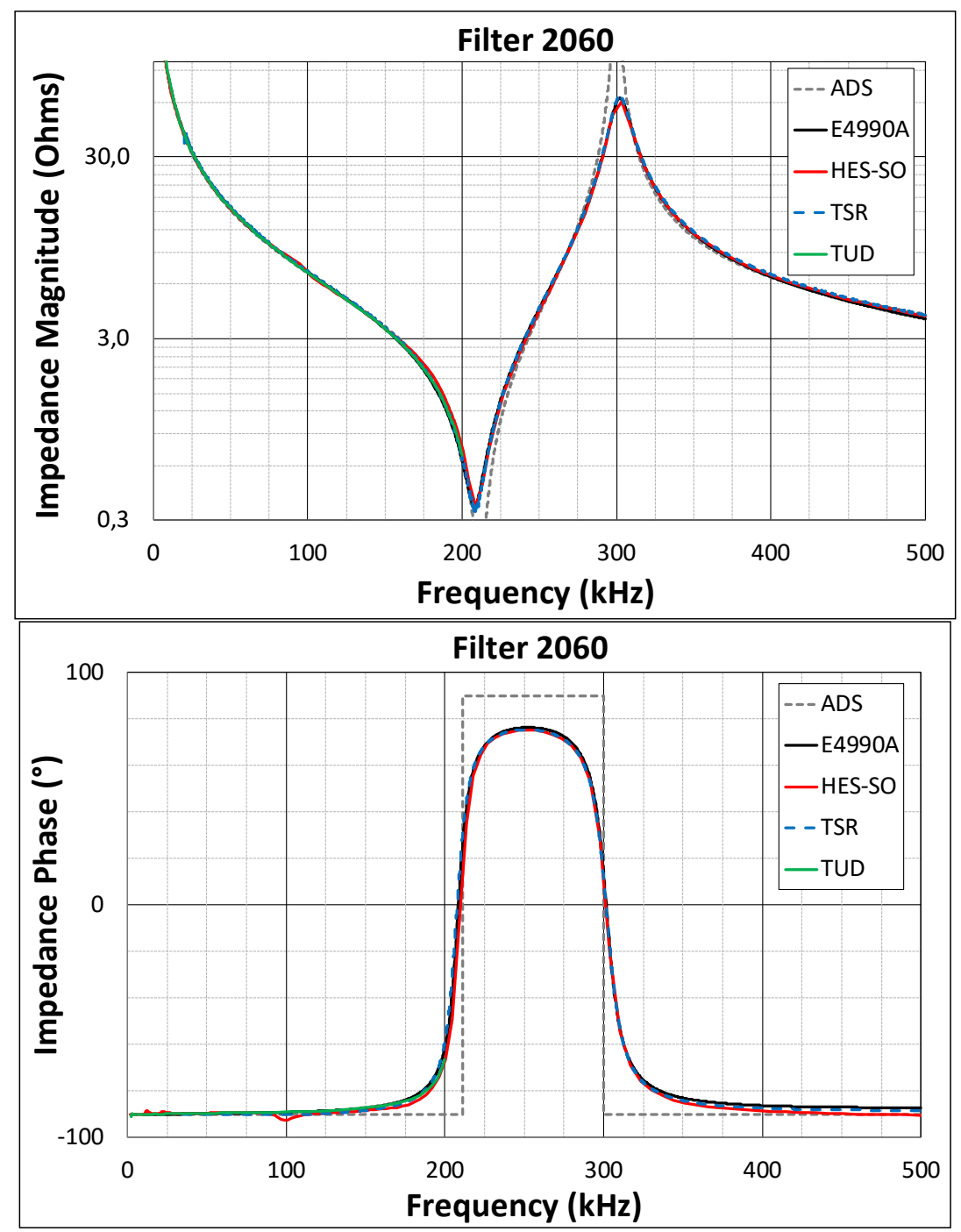

Figure 8. Comparison of simulations and measurement results for filter Reference 2060: (up) magnitude, (down) phase of the impedance.

All the results show very good correlation between measurements and theoretical calculations for the whole frequency range (up to $200 \mathrm{kHz}$ for the three methods, and up to $500 \mathrm{kHz}$ for HES-SO and UPV/EHU methods) and for the wide range of the amplitude of the impedance values. In fact, results are so similar that curves from different methods and results from the precision measurement device partially overlap. Differences in amplitude in the simulations for resonant frequencies are due to the ideal specifications of the components used in the simulation tool, which lead to higher quality factors than in the reality, and for this reason, results from simulations show more abrupt resonances. In any case, the resonance effects of the EMC filters, which represent the most critical situations due to their potential degradation on the communications, are well identified in frequency and evaluated in amplitude by the proposed measurement methods.

The accuracy of the results provided by the methods can be evaluated in Tables 3 and 4, where the errors in magnitude and phase are calculated with respect to the results obtained with the impedance precision meter. All the methods provide measurement errors lower than $5 \%$ in relative amplitude and $2^{\circ}$ in phase, for most of the cases. The mean errors are below $4 \%$ in relative amplitude and $2^{\circ}$ in phase.

As it has been described in Section 1 of this paper, the impedance of the grid has a significant influence on the quality of the communications, mainly if there is a relevant variation within the frequency range of the transmission channel (see Figure 1). Moreover, variations of the grid impedance 
may result in significant variations in the distance range of the transmissions. In the case of the devices that have been designed to play an active role in the frequency domain, such as the EMC filters used in this work, the accurate characterization of the frequency response of the grid impedance is particularly relevant. As a representative example, the frequency-dependent impedance of the Filter 2055 reaches a very low value at $40 \mathrm{kHz}$ (within the CENELEC-A Band), which will contribute to an additional signal attenuation in the order of $20 \mathrm{~dB}$ (see Figure 7). The same fact is observed for Filter 2060 in the FCC frequency band (see Figure 8). If any of these filters are connected near a Smart Meter operating at these frequencies, the communication may be seriously affected. In these situations, the proper characterization of the grid impedance in the field by using a reliable measurement method will provide useful information to guarantee a deep analysis of the communications channel [36].

Therefore, the results of this work provide a proper characterization of NIE in different scenarios, in the frequency range up to $500 \mathrm{kHz}$, in order to contribute with useful information for current configurations of robustness techniques for NB-PLC [57,58] and target mitigation actions [59-61]. A standardized measurement method would also be beneficial for the calibration of LISN-based networks in lab EMC tests (LISN: Line Impedance Stabilization Network). Systematic input impedance measurements could help filters and converters suppliers to design products with an optimal behavior in relation to PLC, and a smaller need to reduce the levels of NIE (Non-Intentional Emissions) to very constringent levels.

\subsection{Use of the Measurement Methods in the Field}

The measurement methods have also been applied in the field. The three systems were used to assess the access impedance in selected access points of different LV grid topologies in Switzerland. Figure 9 shows a representative example of the results obtained in the measurements. As it can be seen from the figure, the impedance values are quite similar for the three methods. In this case, the differences in the results can be caused, not only by the measurement procedure or the data processing of each method, but also by the time variations in the LV grid, because the measurements were not developed synchronously. 


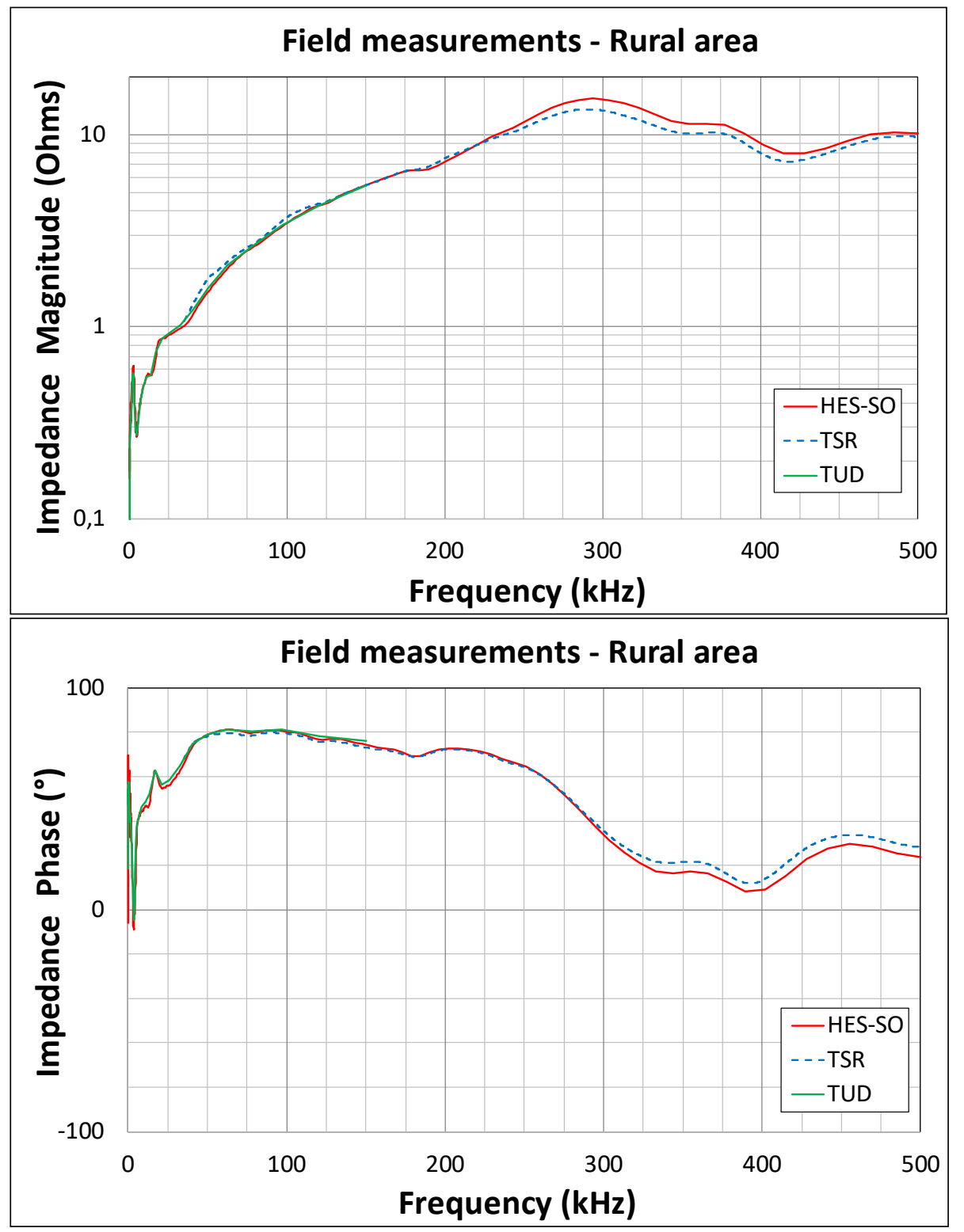

Figure 9. Example of the use of the measurement methods in field trials: (up) magnitude, (down) phase of the impedance.

\section{Conclusions}

Three different methods for the characterization of the grid impedance for the frequency range 9 $\mathrm{kHz}$ to $500 \mathrm{kHz}$ were presented and evaluated in this paper, as there is still no commonly accepted measurement method, validated with lab measurements and supported by standardization agents.

The proposed methods are based on different approaches to the impedance characterization. Hence, although all of them are based on injecting a reference signal into the grid, the measurement methodology, the hardware, the coupling to the grid and the signal processing are different. Method I is based on current injection and Synchronous Demodulation, controlled by an acquisition and processing unit, specifically developed at HES-SO for impedance measurement purposes, providing high resolution and large bandwidth. Method II is mainly based on commercial equipment and an ad-hoc software for signal processing, based on Fourier analysis of synchronized voltage and current acquisitions. Method III is based on a stepwise single frequency sweep for the impedance calculation, the synchronization of the injected frequency to the fundamental frequency of the grid during a 10 cycles interval, and the calculation of voltage and current values by applying the DFT. In summary, the three 
methods try to overcome, with different approaches, the challenges for the characterization of the grid impedance at the frequency range used for NB-PLC, using portable equipment for field measurements.

The accuracy of the methods was evaluated in a controlled and reproducible laboratory scenario: the characterization of the impedance of EMC filters. Results of the measurements from the three methods show very good correlation with both simulations and results obtained with a precision impedance meter, used as a reference of accuracy, which demonstrates the high degree of accuracy of the three proposals to characterize the access impedance of the LV grid.

Author Contributions: Conceptualization, D.d.1.V., D.R. and J.M.; methodology, D.d.1.V., I.F, D.R. and J.M.; software, L.C., I.F. and A.A; validation, I.A., D.R. and R.S.; formal analysis, I.F, I.A., L.C and R.S; investigation, I.F, L.C and R.S; resources, D.R. and A.A; data curation, A.A., I.F., L.C. and R.S.; writing-original draft preparation, D.d.l.V.; writing-review and editing, D.d.l.V., I.F., R.S. and D.R.; visualization, D.d.I.V., I.F. and R.S.; funding acquisition, D.d.l.V., D.R. and J.M.

Funding: This work was financially supported in part by the Basque Government under the grants IT1234-19 and KK-2018/00037, the Spanish Government under the grant RTI2018-099162-B-I00 (MCIU/AEI/FEDER-UE), the Swiss Federal Office of Energy - Energy Research Section, the Swiss Competence Center for Energy Research (SCCER-FURIES) and the German Federal Ministry of Economics and Energy (BMWI, ZF4272801LT6).

Conflicts of Interest: The authors declare no conflict of interest

\section{References}

1. CENELEC. Study report III. In Electromagnetic Interference between Electrical Equipment/Systems in the Frequency Range below 150 kHz; SC205A/Sec0400/R, October 2015; NSAI: Nashua, NH, USA, 2015.

2. IEC/TR. 60725:2012 Consideration of Reference Impedances and Public Supply Network Impedances for Use in Determining Disturbance Characteristics of Electrical Equipment Having a Rated Current $\leq 75$ A per Phase. Available online: https://webstore.iec.ch/publication/3092 (accessed on 20 July 2019).

3. EN 61000-4-7:2002 + A1:2009: Electromagnetic Compatibility (EMC)—Part 4-7: Testing and Measurement Techniques and Interharmonics Measurements. Available online: https://webstore.iec.ch/publication/4228 (accessed on 20 July 2019).

4. Wang, J.; Tyuryukanov, I.; Monti, A. Design of a Novel Robust Current Controller for Grid-Connected Inverter Against Grid Impedance Variations. Int. J. Electr. Power Energy Syst. 2019, 110, 454-466. [CrossRef]

5. Monteiro, H.L.M.; Duque, C.A.; Silva, L.R.M.; Meyer, J.; Stiegler, R.; Testa, A.; Ribeiro, P.F. Harmonic impedance measurement based on short time current injections. Electr. Power Syst. Res. 2017, 148, 108-116. [CrossRef]

6. Liu, N.; Aljankawey, A.; Diduch, C.; Chang, L.; Su, J. Passive Islanding Detection Approach Based on Tracking the Frequency-Dependent Impedance Change. IEEE Trans. Power Deliv. 2015, 30. [CrossRef]

7. Vijayakumari, A.; Devarajan, A.T.; Devarajan, N. Decoupled control of grid connected inverter with dynamic online grid impedance measurements for micro grid applications. Int. J. Electr. Power Energy Syst. 2015, 68, 1-14. [CrossRef]

8. International Electrotechnical Commission, "IEC/TS 62578 Ed. 2.0: 2015 Power electronics systems and equipment-Operation conditions and characteristics of active infeed converter (AIC) applications including design recommendations for their emission values below $150 \mathrm{kHz} . "$. 2015. Available online: https: //webstore.iec.ch/publication/22135 (accessed on 20 July 2019).

9. Rönnberg, S.K.; Amaris, M.H.J.B.H.; Chang, G.W.; Gu, I.Y.H.; Kocewiak, Ł.H.; Meyer, J.; Olofsson, M.; Ribeiro, P.F.; Desmet, J. On waveform distortion in the frequency range of $2 \mathrm{kHz}-150 \mathrm{kHz}-$ Review and research challenges. Electr. Power Syst. Res. 2017, 150, 1-10. [CrossRef]

10. Kotsampopoulos, P.; Rigas, A.; Kirchhof, J.; Messinis, G.; Dimeas, A.; Hatziargyriou, N.; Rogakos, V.; Andreadis, K. EMC Issues in the Interaction Between Smart Meters and Power-Electronic Interfaces. IEEE Trans. Power Deliv. 2017, 32, 822-831. [CrossRef]

11. Hallak, G.; Bumiller, G. Data rate optimization on PLC devices with current controller for low access impedance. In Proceedings of the 2016 International Symposium on Power Line Communications and its Applications (ISPLC), Bottrop, Germany, 29 March-1 April 2016.

12. Lopes, P.A.C.; Pinto, J.M.M.; Gerald, J.B. Dealing with Unknown Impedance and Impulsive Noise in the Power-Line Communications Channel. IEEE Trans. Power Deliv. 2013, 28. [CrossRef] 
13. Zhai, M.-Y. Transmission Characteristics of Low-Voltage Distribution Networks in China Under the Smart Grids Environment. IEEE Trans. Power Deliv. 2011, 26, 173-180. [CrossRef]

14. Pasdar, A.M.; Cavdar, I.H.; Sozer, Y. Power-Line Impedance Estimation at FCC Band Based on Intelligent Home Appliances Status Detection Algorithm Through Their Individual Energy and Impedance Signatures. IEEE Trans. Power Deliv. 2014, 29, 1407-1416. [CrossRef]

15. Lampe, L.; Tonello, A.M.; Swart, T.G. Power Line Communications. Principles, Standards and Applications from Multimedia to Smart Grid, 2nd ed.Wiley: Hoboken, NJ, USA, 2016.

16. CENELEC. Signalling on Low-Voltage Electrical Installations in the Frequency Range $3 \mathrm{kHz}$ to $148.5 \mathrm{kHz}$; Part 1: General requirements, frequency bands and electromagnetic disturbances; CENELEC: Brussels, Belgium, 2011.

17. Cano, C.; Pittolo, A.; Malone, D.; Lampe, L.; Tonello, A.M.; Dabak, A.G. State of the art in power line communications: From the applications to the medium. IEEE J. Sel. Areas Commun. 2016, 34, 1935-1952. [CrossRef]

18. Arechalde, I.; Castro, M.; García-Borreguero, I.; Sendín, A.; Urrutia, I.; Fernandez, A. Performance of PLC communications in frequency bands from $150 \mathrm{kHz}$ to $500 \mathrm{kHz}$. In Proceedings of the 2017 IEEE International Symposium on Power Line Communications and its Applications (ISPLC), Madrid, Spain, 3-5 April 2017.

19. Sendin, A.; Kim, I.H.; Bois, S.; Munoz, A.; Llano, A. Prime v1. 4 evolution: A future proof of reality beyond metering. In Proceedings of the 2014 IEEE International Conference on Smart Grid Communications (SmartGridComm), Venice, Italy, 3-6 November 2014; pp. 332-337.

20. López, G.; Matanza, J.; de la Vega, D.; Castro, M.; Arrinda, A.; Moreno, J.I.; Sendin, A. The Role of Power Line Communications in the Smart Grid Revisited: Applications, Challenges, and Research Initiatives. IEEE Access 2019, 7, 117346-117368. [CrossRef]

21. Fernandez, I.; Uribe-Pérez, N.; Eizmendi, I.; Angulo, I.; de la Vega, D.; Arrinda, A.; Arzuaga, T. Characterization of non-intentional emissions from distributed energy resources up to $500 \mathrm{kHz}$ : A case study in Spain. Int. J. Electr. Power Energy Syst. 2019, 105, 549-563. [CrossRef]

22. Fernández, I.; de la Vega, D.; Arrinda, A.; Angulo, I.; Uribe-Pérez, N.; Llano, A. Field Trials for the Characterization of Non-Intentional Emissions at Low-Voltage Grid in the Frequency Range Assigned to NB PLC Technologies. Electronics 2019, 8, 1044. [CrossRef]

23. Llano, A.; de la Vega, D.; Angulo, I.; Marron, L. Impact of Channel Disturbances on Current Narrowband Power Line Communications and Lessons to Be Learnt for the Future Technologies. IEEE Access 2019, 7, 83797-83811. [CrossRef]

24. Fernández, I.; Angulo, I.; Arrinda, A.; de la Vega, D.; Arechalde, I.; Uribe-Perez, N.; Arzuaga, T. Proceedings of the Characterization of the Frequency-Dependent Transmission Losses of the Grid up to $500 \mathrm{kHz}$ (CIRED-2019), Madrid, Spain, 3-6 June 2019.

25. International Telecommunications Union. ITU-T Rec. G.9903: Narrowband Orthogonal Frequency Division Multiplexing Power Line Communication Transceivers for G3-PLC Networks. Available online: http: //www.itu.int/rec/T-REC-G.9903 (accessed on 20 July 2019).

26. PRIME Alliance Technical Working Group. PRIME 1.4 White Paper. Available online: http://www.primealliance.org/wp-content/uploads/2014/10/whitePaperPrimeV1p4_final.pdf (accessed on 20 July 2019).

27. Cortes, J.A.; Sanz, A.; Estopiñán, P.; Garcia, J.I. Analysis of Narrowband Power Line Communication Channels for Advanced Metering Infrastructure. EURASIP J. Adv. Signal Process. 2015, 2015. [CrossRef]

28. Fernández, I.; Arrinda, A.; Angulo, I.; de la Vega, D.; Uribe-Pérez, N.; Llano, A. Field Trials for the Empirical Characterization of the Low Voltage Grid Access Impedance from $35 \mathrm{kHz}$ to $500 \mathrm{kHz}$. IEEE Access 2019, 7, 85786-85795. [CrossRef]

29. Chu, G.; Li, J.; Liu, W. Narrow band power line channel characteristics for low voltage access network in China. In Proceedings of the International Symposium on Power Line Communications and Its Applications (ISPLC), Johannesburg, South Africa, 24-27 March 2013.

30. Hooijen, O.G. A channel model for the residential power circuit used as a digital communications medium. IEEE Trans. Electromagn. Compat. 1998, 40, 331-336. [CrossRef]

31. Vines, R.M.; Trussell, H.J.; Shuey, K.C.; O’Neal, J.B. Impedance of the Residential Power-Distribution Circuit. IEEE Trans. Electromagn. Compat. 1985, 1, 6-12. [CrossRef] 
32. Tonello, A.M.; Pittolo, A. Considerations on Narrowband and Broadband Power Line Communication for Smart Grids. In Proceedings of the 2015 IEEE International Conference on Smart Grid Communications (SmartGridComm), Miami, FL, USA, 2-5 November 2015. [CrossRef]

33. Atayero, A.A.; Alatishe, A.; Ivanov, Y.A. Power line communication technologies: modeling and simulation of prime physical layer. World Congr. Eng. Comput. Sci. 2012, 2, 931-936.

34. Karakash, J.J. Transmission Lines and Filter Networks; MacMillan: Beijing, China, 1950.

35. Mlynek, P.; Koutny, M.; Misurec, J.; Kolka, Z. Measurements and evaluation of PLC modem with G3 and PRIME standards for Street Lighting Control. In Proceedings of the 18th IEEE International Symposium on Power Line Communications and Its Applications, Glasgow, UK, 30 March-2 April 2014. [CrossRef]

36. Meyer, J.; Khokhlov, V.; Klatt, M.; Blum, J.; Waniek, C.; Wohlfahrt, T.; Myrzik, J. Overview and Classification of Interferences in the Frequency Range $2-150 \mathrm{kHz}$ (Supraharmonics). In Proceedings of the 2018 International Symposium on Power Electronics, Electrical Drives, Automation and Motion (SPEEDAM), Amalfi, Italy, 20-22 June 2018. [CrossRef]

37. Körner, P.M.; Stiegler, R.; Meyer, J.; Wohlfahrt, T.; Waniek, C.; Myrzik, J.M.A. Acoustic noise of massmarket equipment caused by supraharmonics in the frequency range 2 to $20 \mathrm{kHz}$. In Proceedings of the 2018 18th International Conference on Harmonics and Quality of Power (ICHQP), Ljubljana, Slovenia, 13-16 May 2018; pp. 1-6.

38. López, G.; Moreno, J.I.; Sánchez, E.; Martínez, C.; Martín, F. Noise Sources, Effects and Countermeasures in Narrowband Power-Line Communications Networks: A Practical Approach. Energies 2017, 10, 1238. [CrossRef]

39. Mlynek, P.; Fujdiak, R.; Misurec, J.; Slacik, J. Experimental measurements of noise influence on narrowband Power Line Communication. In Proceedings of the 2016 8th International Congress on Ultra Modern Telecommunications and Control Systems and Workshops (ICUMT), Lisbon, Portugal, 18-20 October 2016. [CrossRef]

40. Aloui, A.; Rhouma, O.B.; Rebai, C. Impact of equalization on hybrid communication system for smart grid. In Proceedings of the 2017 International Symposium on Networks, Computers and Communications (ISNCC), Marrakech, Morocco, 16-18 May 2017. [CrossRef]

41. Nikfar, B.; Bumiller, G. Real-time synchronization and multiband detection for narrowband power line communication. In Proceedings of the 2017 IEEE International Symposium on Power Line Communications and its Applications (ISPLC), Madrid, Spain, 3-5 April 2017. [CrossRef]

42. Nikfar, B.; Bumiller, G.; Vinck, A.J.H. An adaptive pursuit strategy for dynamic spectrum assignment in narrowband PLC. In Proceedings of the 2017 IEEE International Symposium on Power Line Communications and its Applications (ISPLC), Madrid, Spain, 3-5 April 2017. [CrossRef]

43. Available online: IEC 61000-2-2:2002+AMD1:2017+AMD2:2018 CSV (Consolidated Version) Electromagnetic compatibility (EMC)-Environment-Compatibility levels for low-frequency conduced disturbances and signaling in public low-voltage power supply systems. Available online: https://webstore.iec.ch/publication/ 63116 (accessed on 20 July 2019).

44. Hallak, G.; Nieß, C.; Bumiller, G. Accurate Low Access Impedance Measurements with Separated Load Impedance Measurements on the Power-Line Network. IEEE Trans. Instrum. Meas. 2018, 67, 2282-2293. [CrossRef]

45. Stiegler, R.; Meyer, J.; Schegner, P.; Chakravorty, D. Measurement of network harmonic impedance in presence of electronic equipment. In Proceedings of the IEEE International Workshop on Applied Measurements for Power Systems (AMPS), Aachen, Germany, 23-25 September 2015.

46. Sigle, M.; Liu, W.; Karlsruhe, K.D. On the impedance of the low-voltage distribution grid at frequencies up to $500 \mathrm{kHz}$. In Proceedings of the 2012 IEEE International Symposium on Power Line Communications and Its Applications, Beijing, China, 27-30 March 2012; pp. 30-34.

47. Zhao, H.; Zhang, W.; Wang, Y. An Effective Method to Calculate Frequency Response of Distribution Networks for PLC Applications. Electronics 2019, 8, 649. [CrossRef]

48. Zhao, H.; Zhang, W.; Wang, Y. Characteristic Impedance Analysis of Medium-Voltage Underground Cables with Grounded Shields and Armors for Power Line Communication. Electronics 2019, 8, 571. [CrossRef]

49. Roggo, D.; Marendaz, L.; Furrer, D. On-Line 2 to $150 \mathrm{kHz}$ Grid Impedance Meter. In Proceedings of the Paper 1417, CIRED Conference 2013, Stockholm, Sweden, 10-13 June 2013. 
50. Capponi, L.; Fernández, I.; Roggo, D.; Arrinda, A.; Angulo, I.; de la Vega, D. Comparison of Measurement Methods of Grid Impedance for Narrow Band-PLC up to $500 \mathrm{kHz}$. In Proceedings of the IEEE 9th International Workshop on Applied Measurements for Power Systems (AMPS), Bologna, Italy, 26-28 September 2018.

51. Roggo, D.; Horta, R.; Capponi, L.; Eggenschwiler, L.; Decorvet, F.; Pellodi, C.; Buholzer, F. Electromagnetic interferences in Smart Grid applications: A case study with PLC Smart Meters and PV energy generation. In Proceedings of the Paper 1285, CIRED Conference 2017, Glasgow, UK, 12-15 June 2017.

52. Zurich Instruments. Principles of Lock-in Detection and the State of the Art. Available online: www.zhinst. com/applications/principles-of-lock-in-detection (accessed on 20 July 2019).

53. Fernández, I.; Arrinda, A.; Angulo, I.; Alberro, M.; Montalbán, J.; de la Vega, D. Measurement method for the characterization of the grid impedance of LV networks for the frequency range for NB-PLC up to 500 kHz. In Proceedings of the CENELEC SC205A WG11 6th Meeting, Viena, Austria, 2 October 2018; Available online: https://collaborate.iec.ch/\#/pages/workspaces/402718/documents/97024 (accessed on July 2019).

54. Fernández, I.; Alberro, M.; Montalbán, J.; Arrinda, A.; Angulo, I.; de la Vega, D. A new voltage probe with improved performance at the $10 \mathrm{kHz}-500 \mathrm{kHz}$ frequency range for field measurements in LV networks. Measurement 2019, 145, 519-524. [CrossRef]

55. Keysight Tecnhologies. Advanced Design System (ADS). Available online: https://www.keysight.com/en/pc1297113/advanced-design-system-ads (accessed on 20 July 2019).

56. Keysight Tecnhologies. E4990A Impedance Analyzer. Data sheet. Available online: https://www.keysight. com/en/pd-2405177-pn-E4990A (accessed on 20 July 2019).

57. Farias, L.D.; Monteiro, L.; Leme, M.; Stevan, S. Empirical Analysis of the Communication in Industrial Environment Based on G3-Power Line Communication and Influences from Electrical Grid. Electronics 2018, 7, 194. [CrossRef]

58. Zhu, Q.; Chen, Z.; He, X. Resource Allocation for Relay-Based OFDMA Power Line Communication System. Electronics 2019, 8, 125. [CrossRef]

59. Bernacki, K.; Wybrańczyk, D.; Zygmanowski, M.; Latko, A.; Michalak, J.; Rymarski, Z. Disturbance and Signal Filter for Power Line Communication. Electronics 2019, 8, 378. [CrossRef]

60. Varajão, D.; Araújo, R.E.; Miranda, L.; Lopes, J.P. EMI Filter Design for a Single-stage Bidirectional and Isolated AC-DC Matrix Converter. Electronics 2018, 7, 318. [CrossRef]

61. Wu, C.; Gao, F.; Dai, H.; Wang, Z. A Topology-Based Approach to Improve Vehicle-Level Electromagnetic Radiation. Electronics 2019, 8, 364. [CrossRef] 